\title{
So different yet so alike: micro and macro labour market outcomes in Germany and Spain
}

\author{
Maia Güell ${ }^{1} \cdot$ Cristina Lafuente $^{2} \cdot$ Manuel Sánchez $^{3} \cdot$ Hélène Turon $^{4} \mathbb{D}$
}

Received: 15 February 2021 / Accepted: 1 October 2021 / Published online: 23 November 2021

(c) The Author(s) 2021

\begin{abstract}
It is well known that German and Spanish labour markets are quite different from a macro point of view. In this paper, we look at these markets through the lenses of individual unstable spells. These include all forms of atypical employment (such as temporary contracts and mini-jobs) as well as unemployment. This combined unstable state captures a fuller picture of the individual experience of volatile income and uncertain employment status than unemployment alone. We find that the survival rates of unstable spells in the two countries are much more similar than those from unemployment. This suggests that the usual focus on unemployment stocks and durations exaggerates the contrast between the two countries in terms of workers' experience of instability. We place these findings in the context of very similar aggregate shocks in the two countries and different policy choices on labour market reforms.
\end{abstract}

\footnotetext{
The data basis of this study is the factually anonymous Sample of Integrated Labour Market Biographies of the Institute for Employment Research (IAB) (version 1975-2017). Data access was provided via a Scientific Use File supplied by the Research Data Centre (FDZ) of the German Federal Employment Agency (BA) at the IAB. We would like to thank Andrea Ichino, Thomas Crossley, seminar participants at EUI, Evi Pappa and one anonymous referee for useful comments. Güell would like to thank the hospitality of the EIEF where part of this work was written.
}

Hélène Turon

Helene.Turon-Lacarrieu@ bristol.ac.uk

Maia Güell

maia.guell@gmail.com

Cristina Lafuente

Cristina.Lafuente@eui.eu

Manuel Sánchez

Manuel.Sanchez@ed.ac.uk

1 CEPR, FEDEA, and IZA, The University of Edinburgh, Edinburgh, UK

2 European University Institute, Fiesole, Italy

3 The University of Edinburgh, Edinburgh, UK

4 IZA, University of Bristol, Bristol, UK 
Keywords Administrative social security data $\cdot$ Unstable spells $\cdot$ duration · Atypical employment $\cdot$ Temporary contracts $\cdot$ Mini-jobs

JEL Classification J21 · J64 · J80

\section{Introduction}

The standard comparison between the German and Spanish labour markets features Spain with a much higher and cyclical aggregate unemployment rate than Germany. In Fig. 1, we show that both countries have had similar aggregate shocks in the last 25 years in terms of real GDP growth, yet the evolution of aggregate unemployment rates is very different, as the left hand panel in Fig. 2 shows. The great recession in Spain was characterized by a sharp rise in the unemployment rate until 2013 followed by a sharp decrease; while in Germany unemployment has been falling since 2005 .

Different labour market institutions are a key factor for understanding the difference in the propagation of shocks to the aggregate unemployment rate. In particular, since the 1980s, Spain and Germany introduced flexibility in their labour markets using very different forms of atypical employment (i.e. non-regular permanent employment). Spain is the OECD country with the highest share of fixed-term or temporary contracts, that is, contracts of fixed duration with negligible firing costs; while Germany is associated with marginal employment and the so-called mini-jobs, which are low paid jobs with a maximum number of hours. Several papers have documented the relationship between temporary contracts/mini-jobs and the unemployment rate. See, for example, Bentolila et al. (2020) for a recent overview of empirical and theoretical research on dual labour markets. Bentolila et al. (2012) offer an analysis of the differential response of unemployment to the Great Recession in France and Spain and its relation to firing costs and the regulation of temporary contracts. Carrillo-Tudela et al. (2021) is a recent and comprehensive analysis of employment transitions after the Hartz reforms in Germany. ${ }^{1}$

Temporary contracts and mini-jobs can be thought as two alternative ways of introducing flexibility in the labour market. They, however, yield different aggregate implications. In Germany, the Hartz reforms and the expansion of mini-jobs have helped reduce unemployment with mixed effects on participation and a rise in the take-up of mini-jobs by women previously out of the labour force (Carrillo-Tudela et al. 2021; Rothe and Wälde 2017). There is no evidence that temporary contracts have increased employment (according to Kahn (2010) with the ECHP in 1996 to 2001). They may have helped to reduce the incidence of long-term unemployment, but not the duration of long unemployment spells in Spain (Güell 2003). Yet, from a worker's point of view, these different contracts offer a very similar experience: they are just different forms of non-stable, non-permanent employment and yield levels of uncertainty and income that are only one step better than those experienced in unemployment.

\footnotetext{
${ }^{1}$ See also, among others, Krause and Uhlig (2012), Krebs and Scheffel (2013), Launov and Wälde (2013) and Bradley and Kügler (2019).
} 


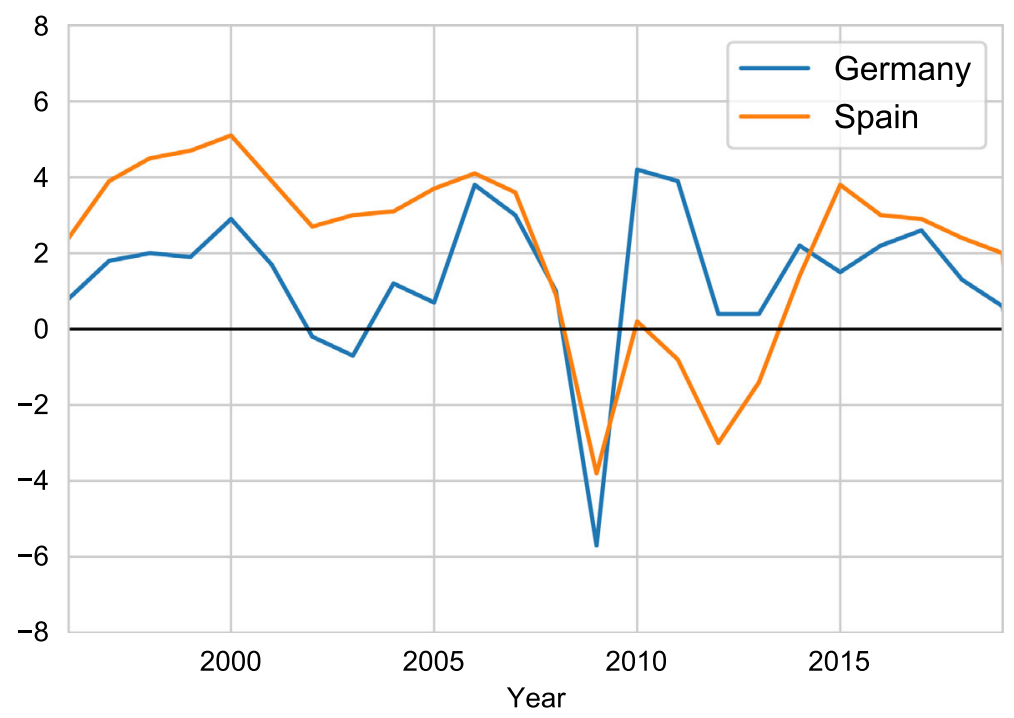

Fig. 1 Real GDP growth (\%). Notes: The figure displays the real GDP growth (\%) by country. Source: IMF
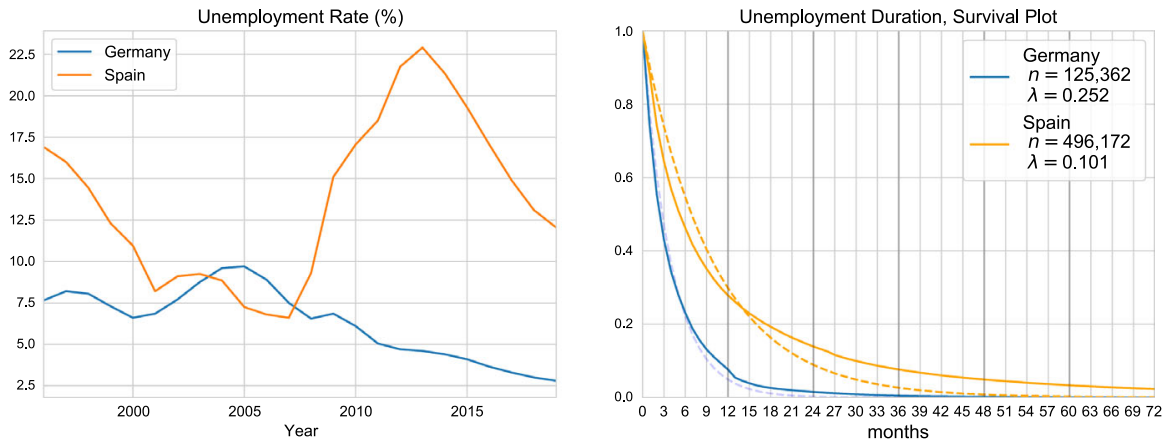

Fig. 2 Unemployment rates and durations. Notes: The left panel displays the unemployment rate (\%) by country . Source: EUROSTAT. The right panel shows the survival plot for all unemployment spells. Dashed lines represent fitted exponential distributions. Sources: SIAB and MCVL administrative data sets

In this paper, we compare the German and Spanish labour markets by studying individual labour market spells in two categories: stable employment spells versus all other spells, that we label as unstable spells. The latter amalgamates any form of unstable job and unemployment. ${ }^{2}$ Forty years ago, before the introduction of atypical forms of employment in Europe, it made sense to focus on employment and unemployment as these two states comprised the bulk of the labour market. However, now that the incidence of atypical forms of employment has grown to a substantial share of the labour market, it is informative to aggregate all forms of labour market experience that are not stable permanent employment. That is, we merge unemployment and all

2 This can also be thought as a natural aggregation from a more formal point of view: mini-jobs can be officially combined with unemployment benefits. And temporary contracts have a limited duration (sometimes only a few days) so there is a churning rate between unemployment and temporary employment. 
types of atypical employment with volatile income and status. We implicitly consider that workers value these states much less than stable employment and engage in (stable) job search while in them. Analysing the distribution of the duration spent in this unstable state and presenting a comparison between Spain and Germany is relevant to an understanding of workers' welfare in the two countries. We use comparable data from each country: administrative data social security records.

A more conventional approach would be to simply focus on unemployment spells. The right panel in Fig. 2 displays the survival rate of unemployment spells by duration. As expected, the probability of leaving unemployment is much lower in Spain at any duration, particularly in the first 3 years. The average hazard rate in Germany is $25 \%$ versus $10 \%$ in Spain. This is a large difference.

Our main finding is that, in contrast with this, the distribution of durations of unstable spells is much more similar in the two countries. This is in a context where aggregate shocks faced by the two economies are very similar in the sample period, but labour market reforms have followed different trajectories. In the face of tight employment legislation on permanent contracts, the use of temporary contracts is substantial in both countries, as is the "mini-job" in Germany. We show that, in spite of these differences, the micro-level experience of unstable spells is more similar between the two countries than the standard picture of unemployment durations would suggest.

The rest of the paper is organized as follows. Section 2 describes in more detail the labour market institutions in both countries and documents the incidence of atypical employment in each country. Section 3 describes the administrative data used in each country. Section 4 presents our survival analysis. Finally, Sect. 5 concludes.

\section{Labour market institutions and incidence of atypical employment}

In this section, we review the labour market institutions in Germany and Spain that are the most relevant for the purpose of our study. We also review the incidence of of atypical employment in the two countries.

\subsection{Labour market institutions}

There is a vast literature that studies the relationship between labour market institutions and labour market outcomes. In this paper, we focus on Germany and Spain, two countries that have different labour market institutions and also took different routes when introducing labour market reforms. We concentrate on labour market institutions that may affect transitions in and out of stable and unstable employment. The most prominent ones are: unemployment insurance, employment protection legislation and atypical employment.

Unemployment insurance is relevant in our context because the literature has clearly established a relationship between its generosity and the duration of unemployment. In the last 20 years, the generosity of unemployment insurance, both as the share of previous income and in terms of its duration, is much higher in Spain than in Germany. 
In fact, Spain is among the most generous OECD countries, while Germany is around the average of OECD.

Employment protection legislation is relevant in our context because it shapes the persistence of stable employment. Moreover, its stringency had an impact on other labour market reforms, as we discuss below. The well-known OECD employment protection index for regular workers has been consistently much higher level in Spain than in Germany over the past two decades (OECD 2020): 2.4 and 2.2, respectively, on a scale from 1 to 3 (where higher is tighter legislation). In fact, Spain is among the OECD countries in which it is more expensive and difficult to fire a permanent worker, while Germany is around the average of OECD. Variations in the regulations applying to the recruitment of temporary workers are even larger than those relating to the dismissal of regular workers. The former is 3.1 in Spain and 1.9 in Germany, on a scale from 0 to 6 (OECD 2020). Looking at changes in EPL over the years 2013 to 2019 , very little change has occurred on the aggregate OECD index, for either regular workers or the hiring of temporary workers in Spain or Germany (OECD 2020, Figure 3.13).

While unemployment insurance and employment protection legislation have evolved over this period, their relative position in the two countries has remained similar. We now turn to the reforms that introduced contracts beyond the typical permanent contract in both countries. Starting in the 1980s and 1990s, several European countries facing high and persistent levels of unemployment reformed their labour markets by introducing different forms of more flexible employment. The typical form of employment was a permanent contract with high firing costs and thus the common and most politically feasible type of reform was to introduce new cheaper contracts for new hires, labelled as atypical employment, while leaving permanent typical employment unaffected. The details on when and how each country undertook these reforms varies.

Spain started reforming the labour market already in the mid-1980s as it was the European country with the highest unemployment rate as well as the most rigid labour market. As is recounted in Dolado et al. (2002), the historical origin of the strong use of temporary contracts in Spain dates back to 1978 and the transition to democracy. The new role afforded to trade unions yielded a steep rise in workers' bargaining power and wages, which was not accompanied by any decrease in job security, as this was deemed politically delicate. This in turn gave rise to very high unemployment rate (circa 20\%) in the early 80 s and a need to reform the labour market. In 1984, a reform liberalizing the use of temporary contracts was deemed as a more viable policy choice than a reform of the permanent contracts. ${ }^{3}$ The new firing-cost-free temporary contracts could be used for any economic activity (not necessarily a temporary one) and had a fixed duration after which the contracts had either to be converted into a permanent one or to end. This important reform has shaped the Spanish labour market, which saw a sharp rise of the prevalence of temporary contracts, exceeding $30 \%$ by

\footnotetext{
3 See Bentolila and Dolado (1994) and Dolado et al. (2002) for a deeper review of the motivations and implications of this reform in Spain).
} 
the early 90s and remaining stable around this level in spite of several reforms in the second half of the 90 s to curb their use. ${ }^{4}$

Temporary contracts in Spain do not generally constitute a stepping stone towards a permanent contract. Güell and Petrongolo (2007) estimate an average quarterly conversion rate of $5 \%$ over the period 1987 to 2002, with higher conversion rates for workers with stronger outside options, e.g. threatening to quit. In order to mitigate the equity concerns raised by the persistence of both stable and unstable employment, subsidies were introduced in 2001 to encourage firms to convert temporary contracts into permanent contracts. Evidence on dual labour markets across OECD countries reviewed in Bentolila et al. (2020) suggests that conversion rates are higher in institutional settings where the gap in termination costs is smaller between temporary and permanent contracts. They cite Germany as an example where temporary contracts are part of a wider vocational educational system, whereas Spain is a labour market where temporary contracts are used by employers as a stable part of the organization of their production. Reforms were undertaken in 2012 in Spain to reduce the EPL gap between the two contract types, by lowering mandatory severance pay for permanent contracts from 45 to 33 days and increasing the termination compensation in temporary contracts from 8 to 12 days (Bentolila et al. 2020 p. 25). We do not expect to see much of its effects in our sample period, 1999-2014.

Now turning to Germany, a series of labour market reforms were implemented during our sample period. These reforms receive the name of Hartz reforms, named after Peter Hartz, the head of the committee that recommended changes to the German labour system. The reforms increased the efficiency of the job search process, cut unemployment benefits for long-term unemployed and allowed for an expansion of flexible forms of employment. Worldwide, the Hartz reforms are known for the introduction of marginal employment, which partially explain the German labour market miracle during the Great Financial Recession. ${ }^{5}$ We briefly summarize descriptions of the reforms that otherwise are plentiful in the literature. The work of Carrillo-Tudela et al. (2021) provides one of the latest descriptions of these reforms. ${ }^{6}$

The creation of marginal employment in Germany goes back to the 1960s. Back then, marginal employment was envisaged to facilitate non-participants engaging in some form of paid work during a period in which labour demand exceeded supply. In general, labour contracts under marginal employment are designed for low-pay employment and have a cap on hours and pay. However, labour earnings under marginal employment are exempted from income tax and social security contributions. Likewise, these earnings do not contribute to the unemployment benefits and pension payments at retirement are reduced. Unemployed workers who receive benefits are

\footnotetext{
${ }^{4}$ See Bentolila et al. (2012a) for an analysis of why fundamental reforms in Spain are difficult, leading the prevalence of marginal changes and Bentolila et al. (2012b) for an overview of reforms in Spain.

5 See Burda and Hunt (2011) and Dustmann et al. (2014) for a discussion on the relation between marginal employment, Hartz reforms and the high level of employment in the German labour market during the Great Financial Recession.

6 The literature has discussed in detail these series of reforms. Burda and Hunt (2011), Caliendo and Hogenacker (2012), Fichtl (2015) and Engbom et al. (2015) provide a general discussion of all the reforms. Caliendo et al. (2016) summarizes the Hartz I-III reforms, and Lietzmann et al. (2016) and Price (2018) focus primarily on the Hartz IV reform.
} 
allowed to work in marginal employment to top up their benefits. ${ }^{7}$ Before the Hartz IV reform in 2005, unemployment insurance in Germany consisted of three layers: unemployment benefits, unemployment assistance and social assistance.

Starting on 1st April 1999, the German Federal Employment Agency set the wage cap for marginal employment contracts to 325 Euros per month with a working time restriction of $15 \mathrm{~h}$ per week. Marginal employment could be used for both temporary and permanent contracts, but temporary employment contracts under marginal employment were restricted to a two-month maximum, or 50 working days by year. ${ }^{8}$ Employees were exempted from social security contributions and employers paid a fixed $22 \%$ rate. In the following paragraphs, we briefly detail each implementation of the Hartz reforms.

The Hartz reforms were implemented gradually and in different stages. Hartz I, which was introduced in 1st January 2003, changed labour regulation in order to enhance temporary employment, implemented occupational training programmes, introduced subsistence payments on behalf of employment agencies and created new forms of employment for elderly workers. It also introduced the set-up of the Personnel Service Agencies (PSAs). These were placement-oriented temporary employment agencies that increased the efficiency of the matching process. In particular, these agencies were supposed to find employment for unemployed individuals and give them training.

Hartz II was introduced in different dates, on 1st January 2003, and 1st April 2003. This stage defined formally two types of labour contracts under marginal employment: mini-jobs and midi-jobs. Mini-jobs paid up to 400 Euros per month (450 Euros in 2013), while midi-jobs paid between 400 and 800 Euros per month. Hartz II introduced three legal modifications: (i) it lifted the threshold for the mini-jobs' maximal wage to 400 Euros, (ii) it eliminated the cap on 15 working hours per week, and (iii) it facilitated the adoption of marginal employment as a secondary form of employment by extending the income tax and social security exemptions for mini-jobs held as a secondary job. Hartz II also made it easier for firms to use marginal employment from an administrative point of view. It facilitated the adoption of marginal employment and the payments of the corresponding taxes and social security contributions. ${ }^{9}$ The social security contribution of employers increased slightly to $23 \%$. Employees only paid $2 \%$ income tax. For midi-jobs, employees paid higher income tax and social security contributions. The aim of the reform was to create incentives to take up marginal employment that led to regular employment and to reduce unregistered work. ${ }^{10}$

\footnotetext{
7 In our sample period, unemployed workers are allowed to work in marginal employment as long as their jobs do not pay more than 165 Euros per month or $20 \%$ of the unemployment benefit amount.

8 Caliendo et al. (2012) indicates that this restriction in the use of marginal employment as a form of temporary employment came as a response to firms substituting regular employment with marginal employment to avoid higher social security contributions in the late 1990s.

9 The Minijobzentrale was created to serve as a unique legal entity responsible for registering marginally employed workers. It also served to deal with all the tax and social security matters related to marginal employment.

10 One aspect that is less known about the Hartz II reform is that it introduced a subsidy for unemployed workers to become entrepreneurs. This "start-up subsidy" scheme was created in addition to an already existing "start-up subsidy" with the goal to promote self-employment. For further details, see Jacobi and Kluve (2006).
} 
Hartz III, introduced in 1st January 2004, restructured the Federal Employment Agency as an entity improving the efficiency in job offer mediation to unemployed workers. The elements of Hartz III increased the efficiency in the matching process and also restructured hiring subsidies to incentivise employers to hire hard-to-place workers, such as older and disabled people.

The Hartz IV reform, introduced in 1st January 2005, tightened conditions on unemployment benefit recipients. In particular, it merged the long-term unemployment assistance benefits with social assistance benefits into one new transfer (ALG II). Unemployment benefits remained unchanged, but the working period to receive benefits approval was shortened from 3 to 2 years. An unemployed person received the so-called unemployment benefits for the first 6-12 months of unemployment. With this reform, each claimant received a standard monthly payment of 345 Euros in West Germany in 2005 (315 Euros in East Germany), plus additional assistance expenses. Thereafter, the person receives a flat-rate means-tested ALG II benefit. Whereas before the reform previous social security contributions were the key criterion for benefit access, after the reform access to benefits and participation in active labour market policy programmes was strictly conditional on a person's ability to work. This was defined as being able to work at least $15 \mathrm{~h}$ a week. In addition, Hartz IV could potentially cut benefits by $30 \%$ for 12 weeks if a person who was able to work refused to enter the activation programme. It also cut benefits if a suitable offer of work proposed by the case worker was rejected by the worker.

In other words, most workers who qualified for unemployment assistance in the old system experienced a dramatic cut in benefits if they remained in unemployment. In practice, Hartz laws explicitly stated that about any work was then considered suitable. Hence, refusal to accept employment led to benefit cuts. Finally, the Hartz IV reform also introduced the so called One-Euro-jobs, which was a form of low pay employment intended to activate benefit recipients by taking up at least some employment in exchange for the ALG II benefits. These jobs paid one Euro per hour worked on top of the unemployment assistance, hoping to attract long-term unemployed workers into regular employment.

After the implementation of the Hartz IV reform, little has been modified regarding these particular aspects of the labour market in Germany. One of those exemptions is that the income level was raised for mini-job employment to 450 Euro in January 2013.

\subsection{Incidence of atypical employment}

In this section, we simply document the incidence of atypical forms of employment in Germany in Spain in the last 25 years. We focus on temporary contracts and mini-jobs. As explained above, temporary contracts are contracts of a fixed duration after which there can be promotion to a permanent job or the contract ends. Temporary contracts have no restrictions on hours or pay, while mini-jobs are job that have a cap on hours and pay. They can be thought as a part-time job with a low wage-a job that allows to earn something extra on the side. 


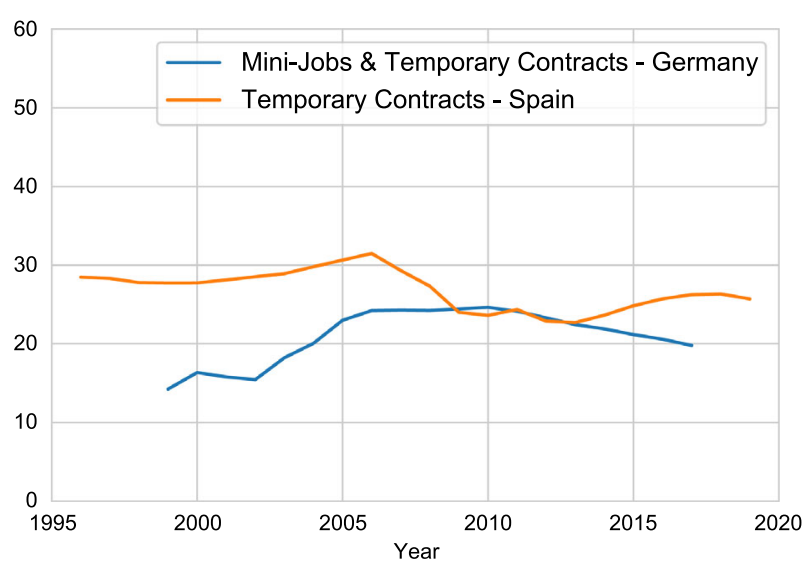

Fig. 3 Incidence of atypical employment (\%). Notes: Incidence of temporary employment and mini-jobs employment among employed workers aged 25-54 . Sources: OECD (2021) and SIAB data

Figure 3 displays the incidence atypical employment among employed workers for both countries. In Spain, this corresponds to the share of temporary contracts, while in Germany, it is the sum of temporary contracts as well as mini-jobs. ${ }^{11}$ We observe that the incidence of atypical employment in Spain is very high, on average around 27 percent in this time period. For Germany, on average around 21 percent of the employed have an atypical contract. So, the incidence of overall atypical employment is higher in Spain than in Germany but not so different in the two countries. Yet, the composition of atypical employment is more different in the two countries. In Spain, all atypical employments are temporary contracts. ${ }^{12}$ In Germany, there are some temporary contracts, but the incidence is much lower, around 8.5 percent on average. In Spain, there are no mini-jobs or marginal employment, while in Germany, it amounts to as much as, on average, 12 percent of employed workers. So the composition of atypical employment in Germany is around 40 percent of temporary contracts and 60 percent of mini-jobs.

Table 1 provides descriptive statistics of the main characteristics of workers in atypical and regular employment. The workforce in atypical jobs includes a higher fraction of females, particularly in Germany, and a higher fraction of foreign-born employees. The average age of the employees in atypical jobs is 5.5 (respectively, 3.5) years younger than in regular jobs. Looking at the breakdown of employment by age groups, we observe a substantially higher share of the 25-35 year-old group and lower share of the over 45 years old in atypical employment, in both countries. In Spain, the education breakdown of employment does not exhibit any sizeable variation across job types, whereas in Germany, atypical jobs seem to attract relatively more workers with less than high school (nearly twice as much) and workers with college education (25\% more) than regular jobs.

\footnotetext{
11 Mini-jobs have been measured using the SIAB data described in Sect. 3.

12 This is true in Fig. 3 and throughout this paper. Formally, there are other forms of atypical contracts (discontinuous employment, training contracts) but these are marginal and targeted at specific groups.
} 
Table 1 Summary statistics: atypical and regular employment

\begin{tabular}{lllll}
\hline & $\begin{array}{l}\text { Spain } \\
\text { Atypical }\end{array}$ & Regular & $\begin{array}{l}\text { Germany } \\
\text { Atypical }\end{array}$ & Regular \\
\hline Female (\%) & 0.51 & 0.47 & 0.63 & 0.45 \\
Foreign born (\%) & 0.15 & 0.09 & 0.16 & 0.08 \\
Age (average) & 37.26 & 42.79 & 39.86 & 43.31 \\
Age (share 25-35) & 0.44 & 0.21 & 0.38 & 0.27 \\
Age (share 35-45) & 0.34 & 0.37 & 0.25 & 0.26 \\
Age (share 45-65) & 0.22 & 0.42 & 0.37 & 0.47 \\
College & 0.22 & 0.21 & 0.27 & 0.22 \\
High School & 0.60 & 0.63 & 0.34 & 0.57 \\
Less than High School & 0.15 & 0.13 & 0.39 & 0.21 \\
$N$ & 116,055 & 337,427 & 121,955 & 416,351
\end{tabular}

Our data also include other information on the specific type of job, industry and "occupational level", but we abstract from these and other characteristics that may change in different employment spells. We only focus on stable, permanent characteristics of workers.

The table displays summary statistics for a cross-sectional sample, containing the first observation of the year 2012

As mentioned before, once labour markets feature enough atypical employment, as it is the case in Germany and Spain, it makes sense to consider amalgamating these in-between states with unemployment when looking at the dynamics labour market states. This is the theme of this paper.

\section{Data and definitions}

For each country, we use their respective administrative social security records. The very nature of these data makes them comparable, although we need to take into account that the coverage might differ. Similarly, we take into account that differences in labour market institutions can affect some classifications in the data. In what follows, we explain in more detail the data sets for each country, and then, we describe the samples used to make them comparable.

The administrative data set from the social security records of Germany is the Sample of Integrated Labour Market Biographies (SIAB, hereafter) provided by the Institute for Employment Research (IAB) for the years 1975-2017. ${ }^{13}$ The SIAB records daily one-person spells. ${ }^{14}$ The SIAB is a $2 \%$ random sample of the German workforce drawn from the Integrated Employment Biographies (IEB). Crucially for this paper, marginal employment spells (i.e. mini-jobs) can be observed for the

\footnotetext{
13 East Germany observations appear after 1991.

14 Because of the rules of the social security notification procedure, employment spells are reported annually, which means that the starting and ending years are always identical (obligation of the employer to submit annual employment notifications). A continuous employment spell may therefore be distributed across several notifications.
} 
first time since April 1999; and information on temporary and permanent contracts is available from November 2011 onwards.

The administrative data set from the social security records of Spain is called the Spanish Continuous Working Life Sample (in Spanish Muestra Continua de Vidas Laborales, MCVL, the Spanish acronym, hereafter) provided by the Social Security Administration. It records daily one person spells. It comprises the complete working histories of a $4 \%$ random sample of working population in each year. Working histories go back to when individuals first entered the labour market up to the end of the sample, which in our case is 2013. Crucial for this paper is that from 1996 there is complete information on the type of employment contract, as before that year this information is often missing.

Sample years For Germany, we focus on the years 2011-2017 when information on both temporary contracts and mini-jobs is available. For Spain, we focus on the years 1996-2013 when information on temporary contracts is reliable. While there is not a total overlap of the sample years in Germany and Spain, the goal of the paper is to analyse the comparability of individual unstable employment spells in the two countries when the aggregate unemployment rates are not necessarily similar.

Labour market states The labour market states in the German data are categorized as follows: employed either full-time or part-time and holding a permanent or temporary contract. Among those in part-time job, the data sets distinguish between those who are in marginal employment (i.e. a mini-job) and those who are not. The other states are: unemployed (receiving benefits or, if not, registered as a job-seeker in an employment agency), ${ }^{15}$ and in non-employment. The latter includes: spells without any type of notifications, and registered in an employment agency as "not unemployed". Workers in partial retirement can be identified (but not those fully retired). Any other state (such as self-employment) will appear as "blank" spell. After the comparability criteria described below, all blank spells present in the data prior to a stable employment will be considered as non-employment.

The labour market states in the Spanish data are categorized as follows: employed with a permanent contract, employed with a temporary contract, ${ }^{16}$ unemployed (receiving benefits), self-employed and retired (receiving a pension). Any other state (such as non-employment or unemployed without receiving unemployment insurance) will appear as "blank" spell. ${ }^{17}$ After the comparability criteria described below, all blank spells present in the data prior to a stable employment will be considered as non-employment.

Measurement unit Our unit of analysis is individual spell. Our samples for the two countries will include the following completed and uncompleted spells: employment spells (in any type of contract), unemployment spells as well as any spell of non-

\footnotetext{
15 Registered job-seekers information is available since 1997 with missing information for years 2005 and 2006.

16 There is a variable that codes the precise type of contract of the worker, which can take hundreds of values. This is because of the several labour reforms that have introduced different types of non-permanent contracts. There is still a clear distinction between jobs that have a defined end date (temporary) and openended contracts (permanent). Here, we simplify all contracts marked as "temporary" as such. We use a similar approach for "permanent" contracts.

17 See Lafuente (2019) for more details.
} 
employment in between employment spells. The idea is to capture workers that might be provisionally out of the labour force but are still attached to the labour market. At the same time, we do not want to simply capture instability due to early career stages and, therefore, we focus on workers who are at least 25 years old. ${ }^{18}$ As explained below, we also restrict workers' age to be 60 years old.

In order to make the two data sets as comparable as possible, we take the following steps:

(i) In the Spanish data, by design, workers included in the data start with an employment spell. While in the German data it is possible to observe entry into the labour force, whether in employment or not. For comparability, in the German data set, we consider workers from the start date of their first employment spell. ${ }^{19}$

(ii) The German data set does not include spells of any civil servants. ${ }^{20} \mathrm{We}$ therefore exclude this category in the Spanish data set. ${ }^{21}$ Moreover, we also exclude employment spells in "permanent discontinuous" contracts since these do not exist in Germany. ${ }^{22}$

(iii) We exclude in the German data workers in apprenticeships and student trainees, given that in Spain until very recently these types of contracts and active labour market policies were not as significant as in Germany.

(iv) Retired workers can be identified in the Spanish data but not in the German data (only if it is partial retirement). In Fig. 4, we explore the inactivity rates by age group in Germany and Spain in 2021 (for previous years this Figure looks very similar). For both countries, at age 60 at least $50 \%$ of the population is inactive. In order to have comparable samples in which retired workers are excluded, the maximum age allowed in our sample is 60 .

(v) In the German data set, self-employment spells are not recorded. ${ }^{23}$ This means that a worker that only has self-employed spells in his/her working life will not be included in the data set. However, workers with working histories featuring some employment spell as a wage-earner as well as other spells of self-employment do appear in the data set (but these spells of self-employment will appear as "blank"). To enhance comparability, in the Spanish data set we exclude workers with only self-employment spells in their working life. As for workers with mixed histories, in the Spanish data we consider self-employment spells in between stable employment spells that are short enough ${ }^{24}$ as non-employment to make it comparable to Germany. That is, these types of spells are considered unstable

\footnotetext{
18 In a recent paper, Bentolila et al. (2021) discuss employment for workers below 25 years in Spain during the last two recessions.

19 In Sect. 3.1, we discuss the possible under-reporting of duration for unstable spell.

20 See Umkehrer (2019).

21 Most civil servants do not appear in the Spanish data set as they are covered by a separate social security system. However, some employees of public firms and casual public workers sometimes do appear in the data. These are the observations we drop from the sample.

22 As mentioned before, these kinds of contracts are targeted at workers of highly seasonal industries, like vegetable canning.

23 See Umkehrer (2019).

24 Less than 2 years, which is $40 \%$ percent of the cases. This is also the maximum duration of a temporary contract. The distribution of durations of self-employment spells is very polarized, reflecting that this
} 


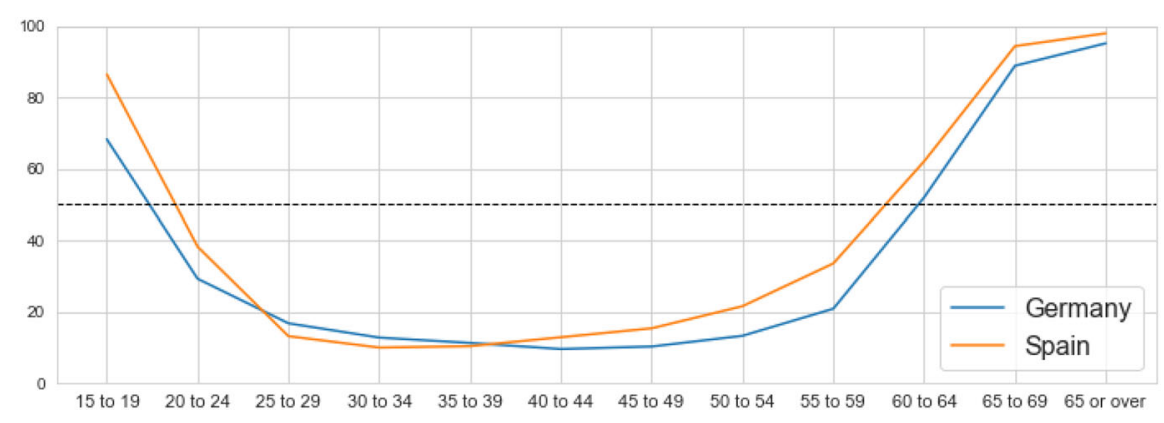

Fig. 4 Inactivity rates . Source: Eurostat (2021)

employment spells in the two countries. As for longer spells in these categories, we exclude them as they would not appear in the German data set.

(vi) Given the sample years used, in the German data set, uncompleted spells will have a maximum duration of 5 years. To enhance comparability, we make the same restriction in the Spanish data.

Our samples for the two countries will therefore include spells for: (i) employed workers (ii) unemployed workers (ii) non-employed in between employment spells (iv) self-employed (for short spells and Spain only). The inclusion of non-employment in (ii) is meant to capture workers who might be provisionally out of the labour force but are still attached to the labour market. Note that we include both complete and incomplete spells. Since our administrative data allow us to follow individuals since the beginning of their labour market activity, our spells are never left censored. They may, however, be right censored if the only unstable spell that we observe for a given individual is not complete by the end of the sample.

Since our unit of observation is one spell per individual, the picture that we present departs from aggregate statistics on stocks: our analysis describes the individual experience of workers flowing into the "unstable" state (see definition below). Since we are giving the same weight to individuals with long spells as to individuals with short spells, we over-represent the latter relative to the former compared to an analysis of aggregate stocks. This explains, for example, why the fraction of spells in nonemployment longer than one year is much smaller than in aggregate statistics. ${ }^{25}$

Other than the labour market status, both data sets include individual characteristics such as gender, age and education that we will use to undertake some heterogeneity analysis.

category covers very stable, almost managerial jobs and very short, contractor-like jobs. The later we consider unstable employment spells.

25 That is, consider a quarterly labour force survey. A worker what has an unstable spell lasting for 2 quarters of more will appear in the stock-based data as unstable in both quarters. However, if a worker with a very short unstable spell in between quarters will not be captured by the labour force survey. Therefore, in our flow-based data, short spells are over-represented. This is because the frequency of administrative data is daily, and no such high-frequency survey data exists. This is explored in detail for Spain in Lafuente (2019). 


\subsection{Unstable spells definition}

We define an "unstable spell" as any combination of atypical employment (temporary, mini-job and short self-employment), unemployment or non-employment in between two stable employment spells (i.e. a permanent job).

There are two exceptions to this general definition related to the incoming and outgoing spells: (i) we also consider uncompleted "unstable spells", that is, spells that have not yet ended into a stable employment by the end of our sample; ${ }^{26}$ (ii) We also consider cases in which the first observed spell in the data for an individual is an atypical employment spell. ${ }^{27}$ That is, unstable spells originate from displacement from stable employment except for new entrants to the labour force, where we start counting their unstable spell from their first atypical employment contract.

This definition is very broad but we find it useful for two reasons. First, atypical contracts, which include any form of non-permanent employment like temporary contracts or mini-jobs, are usually observed with adjacent periods of non-employment or unemployment. Second, our focus on unstable employment makes our cross-country comparison easier since the definition of a stable job is less ambiguous than that of other labour market status.

Please note that our unit of analysis are spells and not whole employment histories. For every worker, we consider one unstable spell, the first unstable spell that is observed in our sample years. A "spell" is defined as the uninterrupted time a person spends registered in one labour state measured in days. Consider a worker who starts working in a temporary job on the 1st of January and ends that job on the 31 st of March. We treat this as one spell-observation of 90 days. In the case of overlapping spells, or spells that end before the previous one starts, we apply the standard order of prevalence approach as described in García Pérez (2008). That is, a worker who simultaneously works in a permanent and a temporary job is classified as permanent for the duration of the permanent spell, as this is considered to be the main job. Similarly, employment spells of any kind take precedence over unemployment spells. ${ }^{28}$ In Spain, we use the expansion approach to unemployment as described in Lafuente (2019). In Germany, the data allow us to differentiate directly between periods of inactivity and unemployment using the Jobseeker History data source. ${ }^{29}$

For consistency, we denote both temporary jobs in Spain and mini-jobs as well as other forms of atypical employment in Germany as Atypical Employment. Similarly, regular permanent jobs are denoted Stable Employment. We thus obtain a collection of spells for each worker within our sample window.

\footnotetext{
26 The share of uncompleted spells in our unstable sample is $27 \%$ in Spain and $14 \%$ in Germany-which reflects that in Spain the sample ends at the peak of the unemployment rate increase in 2013 (see Fig. 2).

27 For both countries, this means that for new entrants into the labour force that start with an nonemployment spell we might be under-reporting the duration of their unstable spell as we cannot observe the time spent in non-employment prior to first employment. The share of new entrants in the unstable spells sample is $21 \%$ in Spain and $27 \%$ in Germany. We believe that this a minor concern given that our sample includes workers aged 25 years or more.

28 Workers receiving unemployment benefits during jobs usually take these in subsidized contracts, so we consider them employed.

29 Arbeitsuchendenhistorik-ASU/XASU.
} 


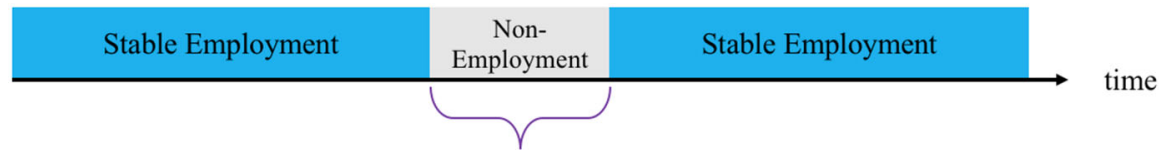

Unstable employment spell

(Only Non-Employment)

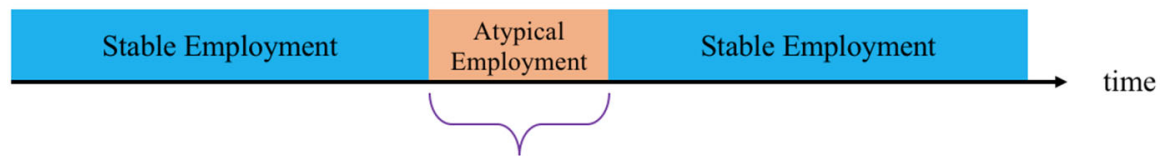

Unstable employment spell

(Only Atypical employment)

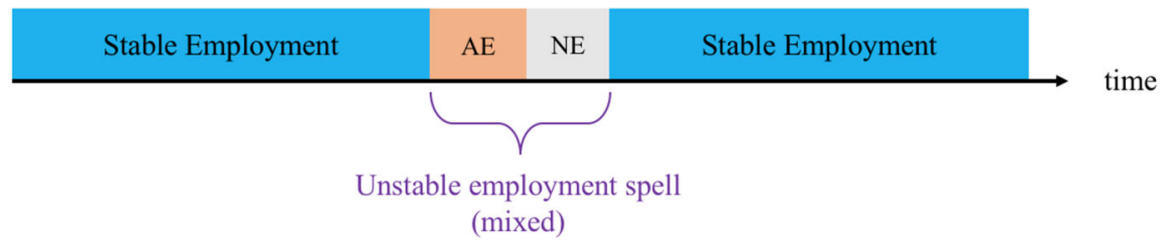

Fig. 5 Completed unstable spells. Notes: Representation of a timeline of a worker with a completed unstable spell. The time period encompassed by the bracket constitutes an "unstable spell" in all three cases

In summary, our definition of an "unstable spell" is as follows:

Definition 1 (Unstable spell) An unstable spell is constituted of any time elapsed between two stable (permanent) employment spells or between entering our sample and the first stable employment spell. Additionally, we also consider uncompleted unstable spells.

Figure 5 represents unstable spells for completed spells. For uncompleted spells the representation would be equivalent except for the last stable spell. Additionally, for cases in which the first observed spell in the data is an atypical employment spell, the representation would be equivalent to Fig. 5 except for the first stable spell. Some unstable spells in our sample are purely composed of non-employment (both unemployment and out of the labour force) or atypical employment, and it may be that these have different dynamics. We will look further into differences between "pure" and "mixed" spells later in Sect. 4.2.

\subsection{Descriptive statistics for Germany and Spain}

The unit of measurement is a unique individual, observed in his or her first spell in the year 2012. This year is selected because it gives the best time overlap of the two data sets. Therefore Tables 2 and 3 correspond to a cross section of the two administrative panels. The characteristics of the two samples look very similar in Table 2. Small differences consist in slightly higher fractions of women and college 
Table 2 Summary statistics: full sample

\begin{tabular}{lll}
\hline & Spain & Germany \\
\hline Female (\%) & 0.46 & 0.49 \\
Foreign born (\%) & 0.12 & 0.10 \\
Age (average) & 42.84 & 42.49 \\
Age (share 25-35) & 0.22 & 0.27 \\
Age (share 35-45) & 0.36 & 0.26 \\
Age (share 45-65) & 0.42 & 0.47 \\
College & 0.18 & 0.23 \\
High School & 0.62 & 0.52 \\
Less than High School & 0.17 & 0.25 \\
$N$ & 611,933 & 544,831 \\
\hline
\end{tabular}

The table displays summary statistics for the first observation of the year 2012, first spell

Table 3 Labour market experience

\begin{tabular}{lllllll}
\hline & $\begin{array}{l}\text { Spain } \\
\text { All }\end{array}$ & Female & Male & $\begin{array}{l}\text { Germany } \\
\text { All }\end{array}$ & Female & Male \\
\hline Work experience & 13.10 & 11.89 & 14.14 & 15.15 & 14.59 & 15.68 \\
Potential work experience & 19.54 & 18.19 & 20.71 & 18.79 & 18.90 & 18.68 \\
Age of entry & 23.30 & 24.26 & 22.48 & 27.39 & 27.64 & 27.14 \\
Part-time (\%) & 0.13 & 0.20 & 0.07 & 0.36 & 0.57 & 0.16 \\
$N$ & 611,932 & 283,374 & 328,559 & 544,831 & 267,699 & 277,132 \\
\hline
\end{tabular}

Work experience and potential work experience is measured in years. Work experience is calculated for employment that is liable to social security records regardless of the type of employment (either stable or atypical employment). The table displays summary statistics for the first observation of the year 2012, first spell

educated (each) in Germany. These differences are unlikely to drive the differences in duration distributions described below.

Table 3 shows that the difference between potential work experience and work experience is markedly larger in Spain than in Germany (6.44 vs. 3.64 years, respectively). The larger gap in Spain is likely related to the greater incidence and duration of unemployment. Part-time work is more prevalent in Germany $(36 \%)$ than in Spain (13\%), since part-time work is widespread among mothers in Germany.

\section{Survival analysis}

The graphs in this section illustrate the survival rates in each country and in each labour market status. The purpose of this exercise is to gauge the speed of turnover in unstable spells and to compare the distribution of spell durations in Spain and Germany. While Sect. 1 showed that the two countries experienced similar macroeconomic shocks, we documented in Sect. 2.1 substantial differences in terms of labour market reforms, as 


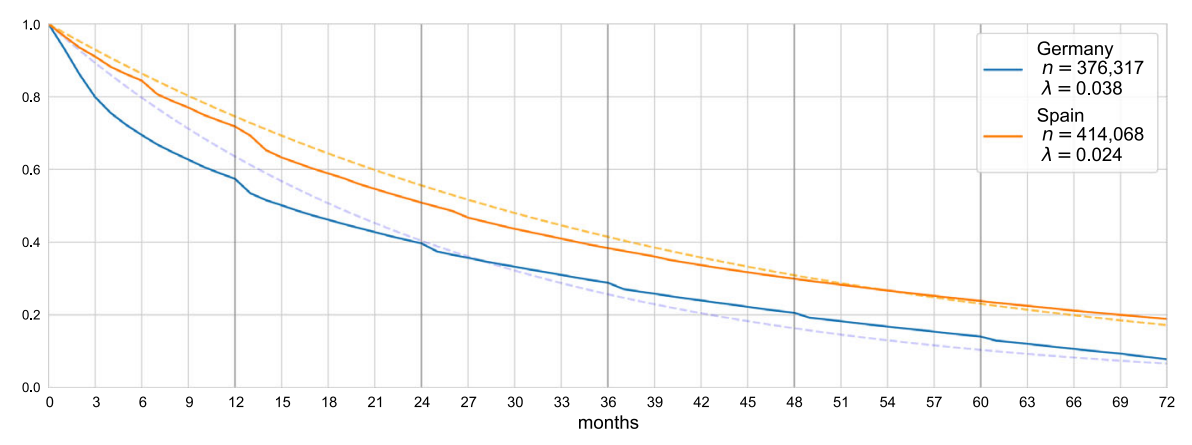

Fig. 6 Survival plot of spell duration, all unstable spells. Notes: The survival plot corresponds to all of the unstable spells. Dashed lines represent fitted exponential distributions

well as important differences in the labour market through the lenses of unemployment: both in terms of aggregates as well as durations, as shown in Fig. 2. In this section, we offer an alternative view of the labour market.

\subsection{Unstable spells}

\subsubsection{Main duration plot}

Figure 6 shows the survival plots in Spain and Germany for unstable spells. We have one spell per individual and each spells ends with a transition to stable employment. As expected, we observe longer durations in Spain than in Germany, with an average hazard rate of $2.4 \%$ for Spain versus $4.0 \%$ in Germany. This is in sharp contrast with the unemployment average hazard rates of $25 \%$ and $10 \%$, respectively, documented in Figure 2.

The main difference between these two plots comes from exits in the first 24 months. Over these first two years, more than $60 \%$ of the inflow in Germany has gained stable employment, whereas only $45 \%$ of the inflow in Spain has done so. Beyond 24 months durations, the two plots are virtually parallel, suggesting that job finding rates among individuals who have been in an unstable spell for more than two years are very similar between the two countries.

The survival plot for Spain follows the exponential fitted line closely while the plot for Germany departs from it substantially, suggesting either some heterogeneity in stable job finding rates across individuals or some negative duration dependence in job finding. There are clear jumps in the Spanish survival plot at each multiple of 12 months. This most probably reflects standard contract length for fixed-term contracts used in Spain as an integer number of years.

This section provides evidence that despite the different nature of mini-jobs and temporary contracts, the micro-level experience following job loss is quite similar in duration. We further investigate this within Germany and find that excluding either 

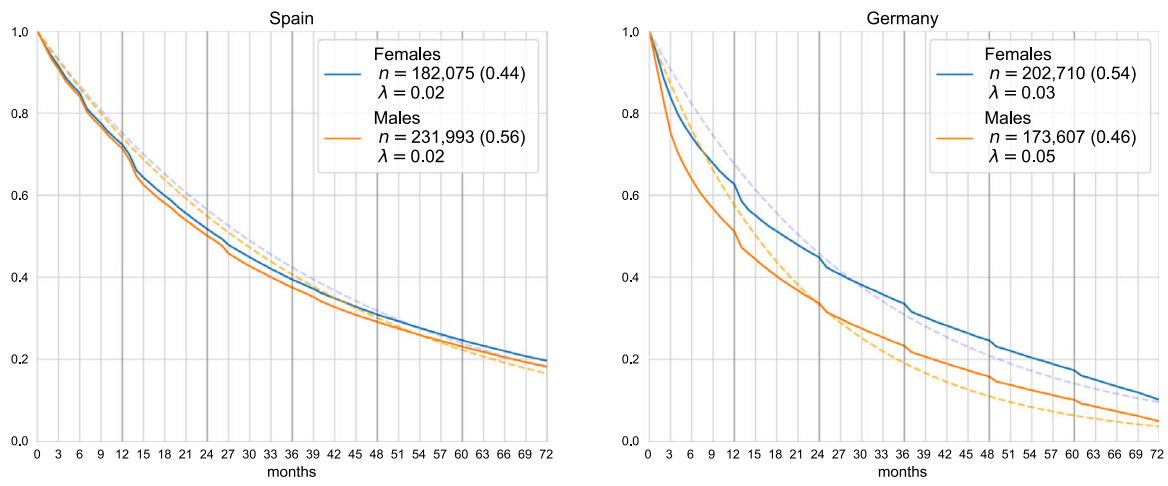

Fig. 7 Survival plot of spell duration, unstable employment, by gender and country. Notes: The survival plot corresponds to unstable spells dashed lines represent fitted exponential distributions
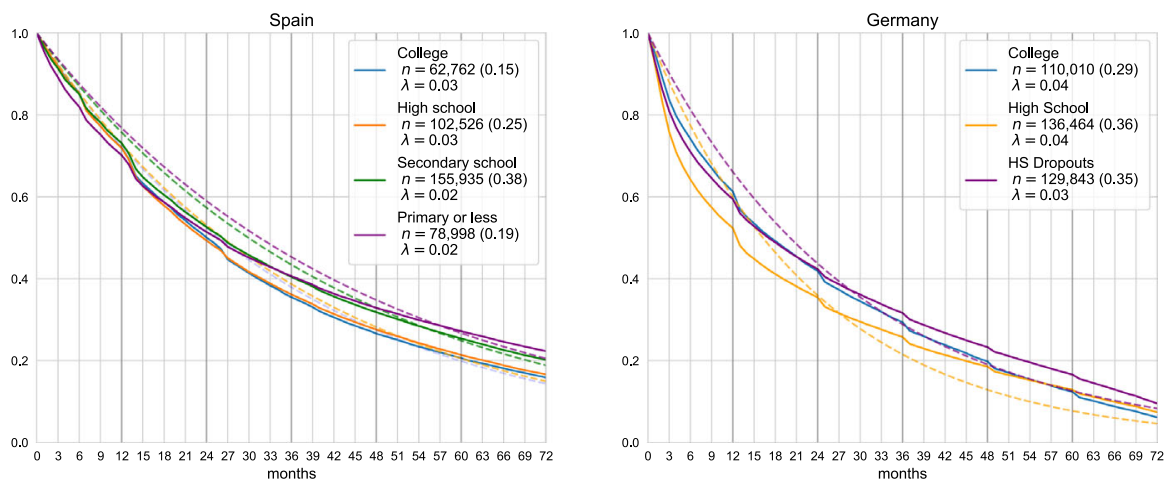

Fig. 8 Survival plot of spell duration, unstable employment, by education and country. Notes: The survival plot corresponds to unstable spells; dashed lines represent fitted exponential distributions

mini-jobs or temporary contracts would lead to similar survival plots, suggesting that these have a comparable contribution in terms of the survival rates. ${ }^{30}$

\subsubsection{Breakdown by characteristics}

Figure 7 shows that, in Spain, gender is not associated with any marked difference in the distribution of durations of unstable spells. There are differences in Germany, with males returning to stable employment substantially faster - the average hazard rate of finding a stable job for males is $5 \%$ versus $3 \%$ for females.

Turning to differences across groups with different levels of completed education, the results shown in Fig. 8 are somewhat unexpected. Education does not yield any substantial difference in survival rates in unstable spells in Spain, while in Germany individuals with college education exhibit longer durations of unstable spells than high school graduates. This difference is small, with average exit rates in the same ball park, peaking at the 0.4 level-i.e. it takes 6 months longer for $60 \%$ of the inflow

\footnotetext{
$\overline{30}$ Results available upon request.
} 

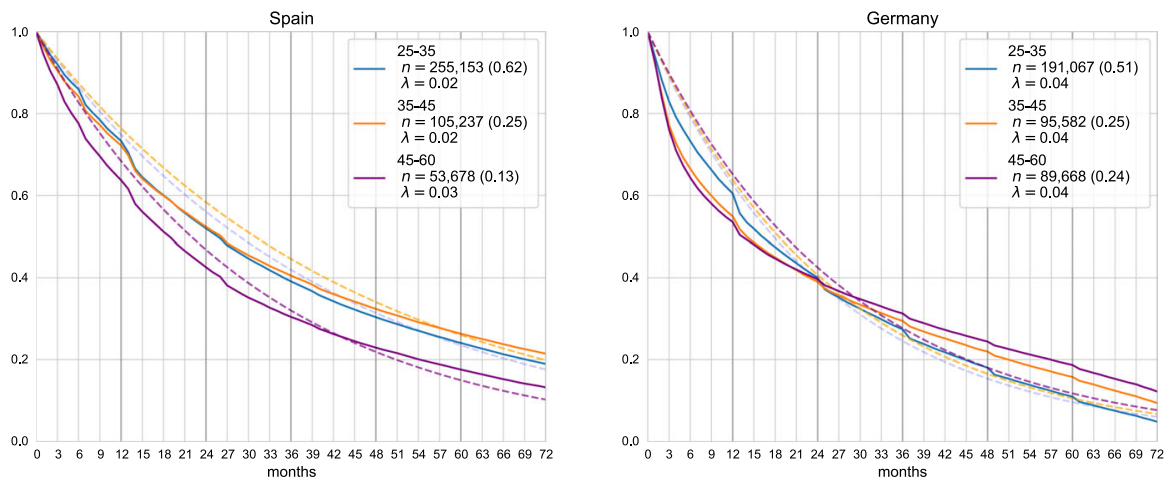

Fig. 9 Survival plot of spell duration, unstable employment, by age and country. Notes: The survival plot corresponds to all unstable spells dashed lines represent fitted exponential distributions

to gain stable employment in the college-educated group than in the group who only completed high school.

As can be seen in Fig. 9, differences across age groups are not substantial, apart from the group of individuals aged 45-60 in Spain, who regain stable employment faster then their younger peers: by 18 months duration in the combined state of nonemployment and temporary employment, half of the 45-60 old inflow has found a stable job, whereas it takes the group of under 4527 months to do so. Beyond 24 months in an unstable spell, differences across age groups in Spain become marginal. In Germany, differences across ages are small throughout the distribution of durations, with the younger groups exhibiting slightly faster exit rates than their older peers in the first two years, and slightly slower exit rates thereafter.

\section{2 "Pure" spells: non-employment and atypical employment}

Since under the umbrella of unstable spells we include spells that are purely nonemployment and purely atypical employment or a mix of these, the purpose of this section is to illustrate the differences between those, by country. These spells do not necessarily include non-employment (see Table 4): in Spain, 53\% of individuals with an unstable spell experience a mix of non-employment and temporary job before acceding to a stable job, while this fraction is only $28 \%$ in Germany. On the other hand, $28 \%$ of unstable spells ${ }^{31}$ in Germany consist in non-employment only; this figure is $17 \%$ in Spain. This is likely to reflect the fact that temporary contracts are the main way out of unemployment in Spain, where $90 \%$ of hires out of unemployment are into temporary employment.

These different figures mean that our comparison of survival plots for each type of "pure" spells does not necessarily relate to the same type of worker: while in Spain the typical experience for ( $83 \%$ of) individuals entering the "unstable" state is a mix of non-employment and temporary jobs, in Germany it is more often a "pure" spell, be it a non-employment spell (for $28 \%$ of the inflow) or a spell of atypical employment

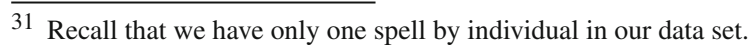


Table 4 Composition of unstable spells

\begin{tabular}{lll}
\hline & Spain & Germany \\
\hline Only atypical & 124,084 & 127,192 \\
& $(0.30)$ & $(0.34)$ \\
Only non-employment & 72,046 & 105,555 \\
& $(0.17)$ & $(0.28)$ \\
Mixed & 217,938 & 143,570 \\
& $(0.53)$ & $(0.38)$ \\
\hline
\end{tabular}

(for 35\% of individuals). The comparisons of the survival plots in "pure" spells thus include a sample selection bias.

\subsubsection{Non-employment}

Pure non-employment spells exhibit very different durations in Germany and in Spain. Figure 10 shows that it takes 4 months for $60 \%$ of individuals to leave this state in Germany, whereas it takes 10 months in Spain. Only 5\% of individuals entering nonemployment in Germany experience a duration in this state of over two years whereas $20 \%$ do so in Spain. The survival plot for Spain is fairly well approximated by an exponential survival function, but this is not the case for that of Germany, where hazard rates of finding a stable job from non-employment decrease with duration. This suggests the presence of one or both of duration dependence and heterogeneity in the hazard of leaving non-employment in this country.

The contrast between the two countries seen in this diagram is consistent with the picture of unemployment dynamics shown in Fig. 2. The median duration before acceding to stable employment is 2.5 months in Germany versus 7 months in Spain, whereas the median duration until exit from unemployment to any kind of employment was 2.6 and 6.9 months, respectively, for Spain and German. On the other hand, when we focus on the combined state of unemployment and atypical employment which we call "unstable" spell, the median durations are 14 and 25 months, respectively, for Germany and Spain (see Fig. 6). In our view, the description of unstable spells is a useful complement to the usual focus on unemployment duration, since both unemployment and atypical employment yield unpredictable (and low) income flows for the individual.

\subsubsection{Atypical employment}

Figure 11 contrasts with Fig. 10 in that spells in atypical employment are much more similar in the two countries. It takes 12 months in both countries for $40 \%$ of the inflow to find stable employment. In Spain, we observe sizeable jumps in the survival function at 6 and 12 months durations. These are standard lengths of temporary contracts, which explains these mass points in the distribution of durations. At 12 months, over $15 \%$ of the Spanish inflow transits to stable employment. This is consistent by the evidence in Güell and Petrongolo (2007) cited above in Sect. 2 since this diagram only looks 


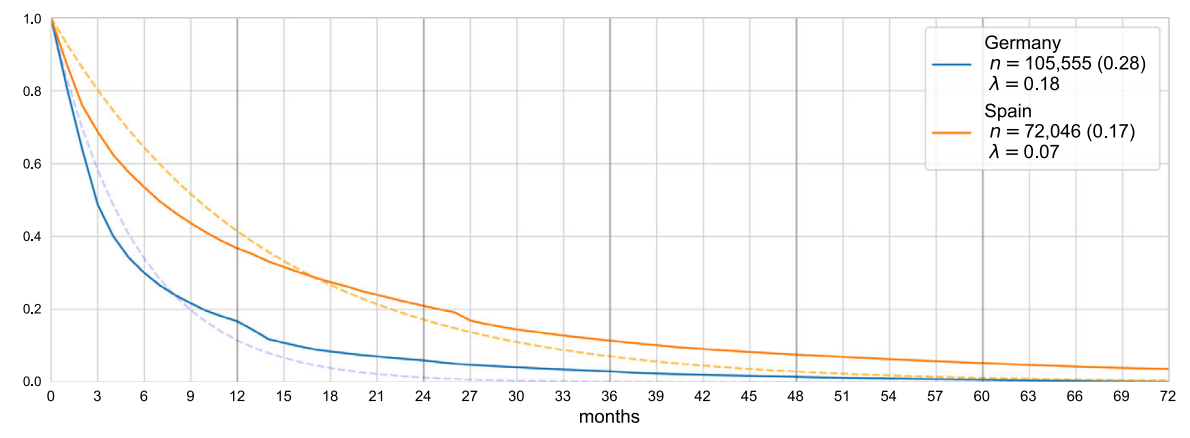

Fig. 10 Survival plot, "pure" non-employment. Notes: The survival plot corresponds to purely nonemployment spells-without any atypical job spells. Dashed lines represent fitted exponential distributions

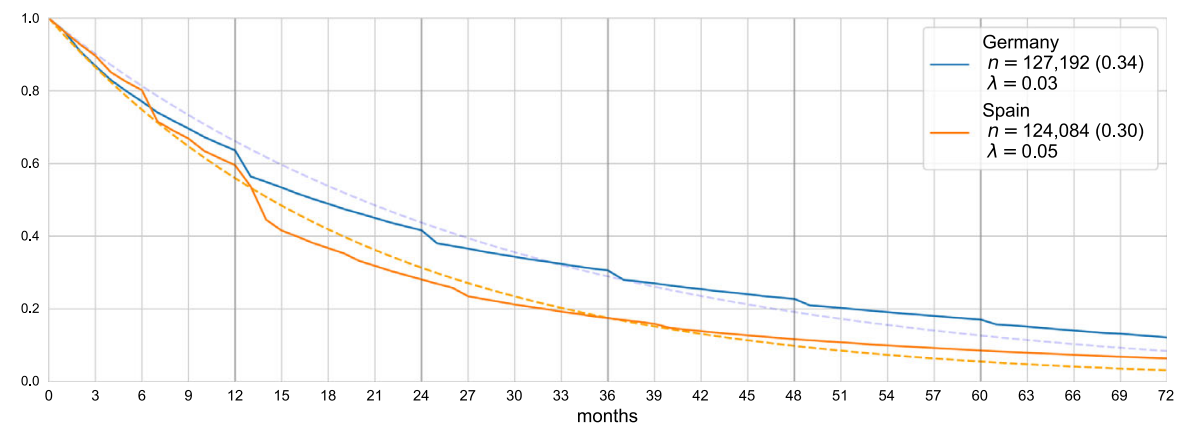

Fig. 11 Survival plot, "pure” atypical employment. Notes: The survival plot corresponds to purely atypical jobs spells_-without any unemployment or non-employment. Dashed lines represent fitted exponential distributions

at individuals (re)gaining stable employment without an intervening unemployment spell, thus presumably individuals most attached to the labour force and with the strongest outside options.

Beyond this hiatus, the two survival plots are nearly parallel and the difference remains until very long durations: in Germany, $12 \%$ of the inflow experiences a spell of "pure" atypical employment which lasts over 6 years, whereas the corresponding figure for Spain is $8 \%$.

\section{Conclusion}

In this paper, we highlight the fact that two countries can look very different in terms of aggregate labour market outcomes and unemployment durations, while not look so dissimilar when examined at the micro-level in terms of individual employment histories, particularly if one focuses on unstable spells, i.e. spells including both unemployment and unstable employment. Aggregate unemployment statistics differ sharply between Spain and Germany. Nevertheless, an individual losing a stable job can expect a much more similar distribution of spell length before regaining stable employment than these 
statistics suggest. In both countries, atypical forms of employment have become very common, in the form of temporary contracts in Spain and both temporary contracts and mini-jobs in Germany. Our results suggest that, once these atypical jobs have been taken into account as another form of unstable labour market state, the individual experience of instability - in terms of its expected distribution of durations-is less different between the two countries than aggregate unemployment figures would imply.

The descriptive analysis presented in this paper opens two avenues for future research. First, acknowledging heterogeneity in job finding rates and in preferences for stable employment, we plan to disentangle the contributions of individual heterogeneity and duration dependence to the evolution of individual hazard rates over the spell duration. We explore these important issues in our next paper (see Güell et al. 2021). Second, our results suggest that there is scope for more theoretical research to further our understanding of labour market policies and the volatility of employment as well as income.

\section{Declarations}

Conflict of interest Maia Güell declares that she has no conflict of interest. Cristina Lafuente declares that she has no conflict of interest. Manuel Sánchez declares that he has no conflict of interest. And Hélène Turon declares that she has no conflict of interest. This article does not contain any studies with human participants or animals performed by any of the authors.

\section{References}

Bentolila S, Cahuc P, Dolado JJ, Le Barbanchon T (2012) Two-tier labour markets in the great recession: France versus Spain. Econ J 122(562):F155-F187

Bentolila S, Dolado JJ (1994) Labour flexibility and wages: lessons from Spain. Econ policy 9(18):53-99

Bentolila S, Dolado JJ, Jimeno JF (2012a) Reforming an insider-outsider labor market: the Spanish experience. IZA J Eur Labor Stud 1:1-29

Bentolila S, Dolado JJ, Jimeno JF (2012b) The new new labour market reform in Spain: objectives, instruments, and shortcomings. CESifo DICE Rep 10(2):3-7

Bentolila S, Dolado JJ, Jimeno JF (2020) Dual labour markets revisited. Oxford research encyclopedia of economics and finance

Bentolila S, Felgueroso F, Jansen M, Jimeno JF (2021) Lost in recession: youth employment and earnings in Spain. Mimeo, New York

Bradley J, Kügler A (2019) Labor market reforms: an evaluation of the Hartz policies in Germany. Eur Econ Rev 113(C):108-135

Burda M, Hunt J (2011) What explains the German labor market miracle in the great recession? CEPR discussion paper 8520

Caliendo M, Hogenacker J (2012) The German labor market after the great recession: successful reforms and future challenges. IZA discussion paper 6810

Caliendo M, Künn S, Uhlendorff A (2012) Marginal employment, unemployment duration and job match quality. IZA discussion paper 6499

Caliendo M, Künn S, Uhlendorff A (2016) Earnings exemptions for unemployed workers: the relationship between marginal employment, unemployment duration and job quality. Labour Econ 42:177-193

Carrillo-Tudela C, Launov A, Robin J-M (2021) The fall in German unemployment: a flow analysis. Eur Econ Rev 132:103658

Dolado JJ, García-Serrano C, Jimeno JF (2002) Drawing lessons from the boom of temporary jobs in spain. Econ J 112(480):F270-F295 
Dustmann C, Fitzenberger B, Schönberg U, Spitz-Oener A (2014) From sick man of europe to economic superstar: Germany's resurgent economy. J Econ Perspect 28(1):167-88

Engbom N, Detragiache E, Raei F (2015) The German labor market reforms and post-unemployment earnings. IMF working paper 162

Eurostat (2021) Inactive population as a percentage of the total population, by sex and age. https:// ec.europa.eu/eurostat/databrowser/bookmark/e17f3a4b-7406-46b3-b480-975cece81c61?lang=en. Accessed 01 July 2021

Fichtl A (2015) Mini- and midi- jobs in Germany. Fores policy paper 3

García Pérez JI (2008) La muestra continua de vidas laborales: una guía de uso para el análisis de transiciones. Rev Econ Apl 16(1):5-28

Güell M (2003) Fixed-term contracts and the duration distribution of unemployment. Available at SSRN 311581

Güell M, Petrongolo B (2007) How binding are legal limits? transitions from temporary to permanent work in spain. Labour Econ 14(2):153-183

Güell M, Lafuente C, Sánchez MA, Turon H (2021) A non-parametric variance decomposition of unstable employment cycles. Mimeo, New York

Jacobi L, Kluve J(2006) Before and after the Hartz reforms: the performance of active labour market policy in Germany. RWI discussion paper 41

Kahn LM (2010) Employment protection reforms, employment and the incidence of temporary jobs in europe: 1996-2001. Labour Econ 17(1):1-15

Krause MU, Uhlig H (2012) Transitions in the German labor market: structure and crisis. J Monet Econ 59:64-79

Krebs T, Scheffel M (2013) Macroeconomic evaluation of labor market reform in Germany. IMF Econ Rev 61(4):664-701

Lafuente C (2019) Unemployment in administrative data using survey data as a benchmark. SERIEs 11:115153

Launov A, Wälde K (2013) Estimating incentive and welfare effects of nonstationary unemployment benefits. Int Econ Rev 54:1159-1198

Lietzmann T, Schmelzer P, Wiemers J (2016) Does marginal employment promote regular employment for unemployed welfare benefit recipients in Germany? IAB discussion paper 18

OECD (2020) OECD employment outlook 2020, 2020th edn. OECD Publishing, Paris

OECD (2021) Temporary employment (indicator). https://doi.org/10.1787/75589b8a-en

Price B (2018) The duration and wage effects of long-term unemployment benefits: evidence from Germany's Hartz IV reform. Mimeo, New York

Rothe T, Wälde K (2017) Where did all the unemployed go? Non-standard work in germany after the hartz reforms, Technical report, IAB-discussion paper

Umkehrer M (2019) Heterogenous effects of entering the labor market during a recession: new evidence from Germany. CESifo Econ Stud 65(2):177-203

Publisher's Note Springer Nature remains neutral with regard to jurisdictional claims in published maps and institutional affiliations. 